\title{
English as a Language of Diplomacy
}

\author{
Zhanna Dossan* PhD. Candidate \\ School of Political Science and Public Administration, Wuhan University, Wuhan, Hubei, 430072 China
}

\begin{abstract}
This research intends to present the position of English language in terms of its diplomacy. The method that is deployed in this research mixed, i.e., qualitative and quantitative, where the survey and interviews were performed with the individuals. The focus of the questionnaire was on the overall perception of the English language as the diplomatic language, while the focus of the interviews was on the difficulties the participants experience based on their experience overseas. The findings showed that use of English as the language is based on its major use in the diplomatic relation is the result of strategic, political, cultural, economic or other power's domination in the international connections. It is primarily because in the written interaction for the diplomatic affairs, usage of language is general clearly determined (frequent in mutual treaty and deal). In a general way, it depends on one of the basic rules of modern foreign rules - the law of sovereign justice of countries. Similarly, interview findings showed that the experiences differed in interactions with people that belong to various linguistic backgrounds.
\end{abstract}

Keywords: Diplomatic Language, English, Experience, Reflection

DOI: $10.7176 / J L L L / 73-03$

Publication date: November $30^{\text {th }} 2020$

\section{Introduction}

The most famous language is English among the diplomatic languages and it is considered as the first and foremost choice for elite and masses. English is known by 1.1 billion people as foreign or second language and it outnumbers the native speakers of Europeans in addition to the native speakers of 375 million (Hasan\& Iberahim, 2019). The language of prestige and power is considered English as it has become a global language and it also plays a role of international gatekeeper to economic as well as social progress alongside a huge tolerance for linguistic variations. English is currently dominated a language of a world and this matter is undoubted. In majority of the international organizations, this is playing working or an official part (Drave, 2017). Since World War 11, French has been replaced by English as diplomacy's lingua franca (Kirkpatrick et al., 2017).

There is major significance of the usage of the language in diplomacy, there is no simplicity of language, it is responsible for transmitting thoughts, or it is considered as communication instrument, it is also considered as diplomatic vocation's essence, from our profession's early beginnings. There had to be trained and educated first envoys of mediaeval Dubrovnik consuls, Roman legates, Egyptian pharaohs, etc. (Mori, 2020). The language allows to overcome the differences and help in forming an integrative environment.

The issue of communication between individuals who belong to distinct mother tongues can be overcome by various ways. But there is no ideal way. There can be a solution which can be interlocutors who speak other's language (de Carles, 2019). There can be problem due to: it may be complex for applying in multilateral diplomacy, possible political implications are present, there may be no adequate knowledge of the language, one possesses significant and immediate benefit and the other makes concession. A third, neutral language is used by both sides as it is a second possibility. Full linguistic knowledge as well as control is possessed by neither side which leads to the probable consequential misunderstandings as it may be a potential problem. However, due to its political benefits, there is frequent application of this method in international practice. There is also a wide usage of a third formula which is to use interpreters, especially, at high political level, for negotiations or in multilateral diplomacy- not because of the equity's reasons, but due to the fact that foreign languages are not spoken often by statesmen and politicians. To understand the use of the English as a language of diplomacy, this research was conducted. Previous researches that have analyzed the language as diplomatic has not considered the experiences of the individuals who have travelled or reside at places where English was the major language. Thereby, using the reflective model, this research intends to present the position of English language in terms of its diplomacy (Figure 1). 


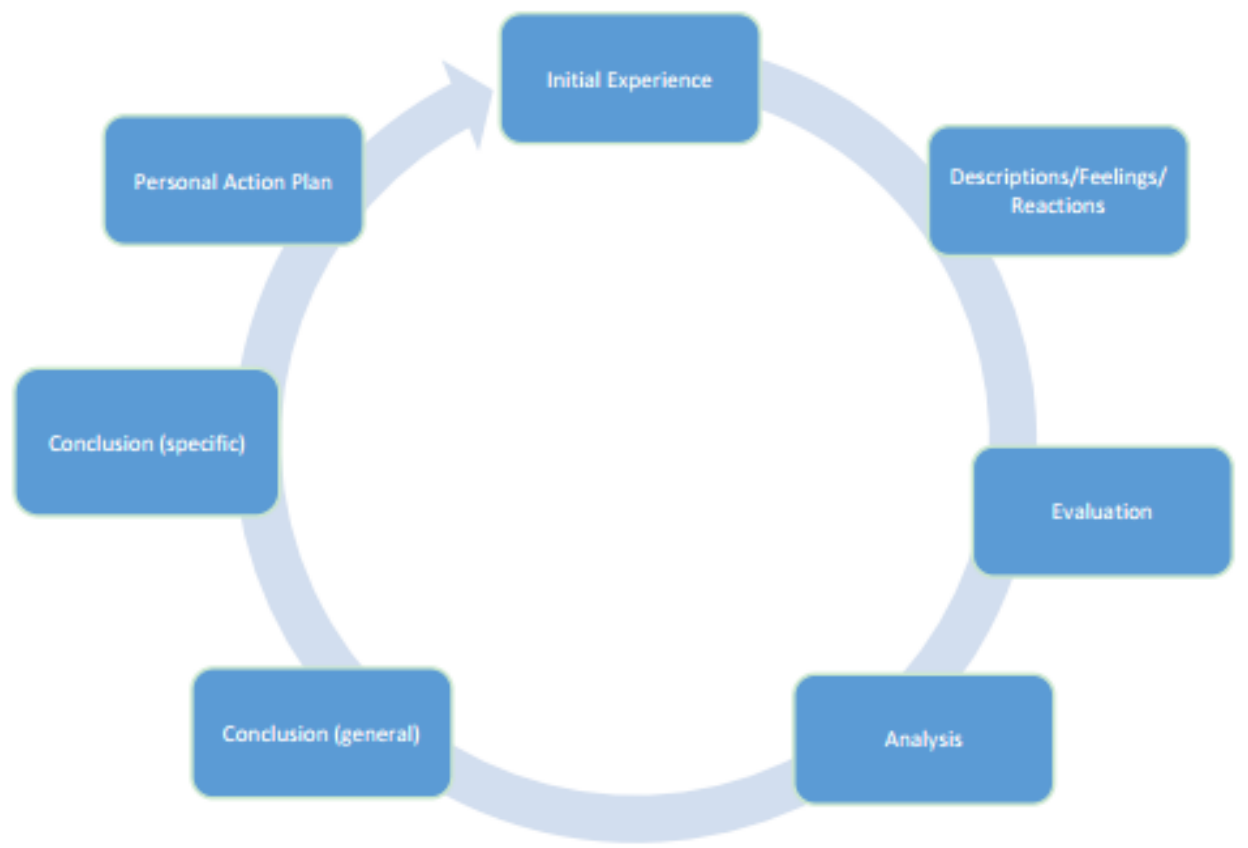

Figure 1: Gibbs Reflective Model

\section{Literature Review}

In diplomacy, there was a beginning of the rise of English, when English and French were used in writing the Treaty of Versailles, as at that time the dominant language was utilized in diplomacy after the World War 1. Due to the evident international role of nations of English-speaking i.e., the Commonwealth of Nations and the United States after World War 11 especially in developing the internet and in the United Nations' organization and establishment, there was advancement in the widespread use of English. One of the UN's six official languages is English, and with French it is considered one of the two working languages and the others include Spanish, Russian, Chinese, and Arabic (Walkinshaw, Mitchell, \& Subhan, 2019). The present lingua franca of aviation, technology, science and international business is English.

There are number of sources of the modern trend of utilizing English outside of the countries of Englishspeaking. Because of the cultural, economic and military dominance of the U.S.A, there was its widespread use in the latter half of the $20^{\text {th }}$ century. Some regards English as non-official international lingua franca which owe to geopolitical, economic and cultural power of developed Western nations' majority in business as well as in world financial institutions (Friedrich, 2016). Consequently, English status of de facto as lingua franca has been moved internationally. Major scientific journals of the world get published in English as the language is hugely dominant in technological as well as scientific communications (Oglesby, 2016). International Air Traffic Control communications' lingua franca is also English. French was considered as the international relations' prime language from the $17^{\text {th }}$ century to $20^{\text {th }}$ century. An important ordinance was passed by Francois the First in 1539 in this context in French language's history: According to decree of the Villers-Cotterêts Ordinance, French must be the language of all French administrative documents. In the language of French, a crucial turning point was this ordinance which created a sense of nationalism and made it an official language in the country (Kulinska, 2017). There was a good time of French language globally when the leading European power was French from 1550 to $19^{\text {th }}$ century. In the $17^{\text {th }}$ century, French was the language of international relations as well as diplomacy for this reason. For two major reasons, there was wide usage of French in international diplomacy: first and foremost, due to the fact that a huge political power was French (Dasselaar, 2016). There was a common use of the language in Europe when there was reign of Louis XIV from the $18^{\text {th }}$ century. Afterwards, the language was further spread by Napoleon. There was plunge in the usage of French in international treaties and the USA emerged following the First World War and there was writing of the Treaty of Versailles in French as well as in English. Moreover, the second prime reason is precision's and clarity's language: several conjunctions, adverbs and determines are used by it, and parts of sentences are linked and their relationships are clarified (Kisin, n.d). There is a link alongside phenomenon of foisonnement" (expansion) in translating English to French and the translation of French remains on average which is $15 \%$ lengthy as compared to the source text. Ambiguity is more to be created by English and there can be bluntness in its concision and it was explained as "the enemy of polite discourse" in the program. These days, few French ghosts (rapprochement, etiquette, coup, regime and others) still haunt the language of English diplomacy in spite of the fact that French language has lost 
a lot of its prestige. In many ways, there can be interpretation of the term "language of diplomacy" (Mori, 2020).

\section{Methodology}

The method that is deployed in this research mixed, i.e., qualitative and quantitative, where the survey and interviews were performed with the individuals. The sample that is selected in this research is of individuals who have travelled overseas of education or traveling purposes. The primary reason for using this design is that it helps to draw comprehensive findings. The outcomes drawn are easy to interpret and followed. The focus of the questionnaire was on the overall perception of the English language as the diplomatic language, while the focus of the interviews was on the difficulties the participants experience based on their experience overseas.

\subsection{Procedure}

The researcher reached out to different universities with international exchange program. The objective of the study, and the purpose it intends to achieve were communicated, following which the list of students was provided by the HR department of the university. These students were reached out through email and phone calls for the participation in the research. They were also asked to present a written consent form. The survey form was shared on the email while interviews were held on Zoom session given the pandemic. This helps in the timely and cost-effective collection of the data. Total 300 students were included for the survey, while the interview had 20 students and faculty. The inclusion of both the demographic group helps providing a comprehensive set of information.

\subsection{Analysis}

The analysis of the survey data was held by entering the data into the excel file, while the thematic approach was used for the analysis of the interview findings. This helped in providing a comprehensive evaluation concerning the English as a language of diplomacy.

\section{Results}

The gender analysis is presented in the table 2, which shows that most of the respondents were male, while the number of female was low (Table 2).

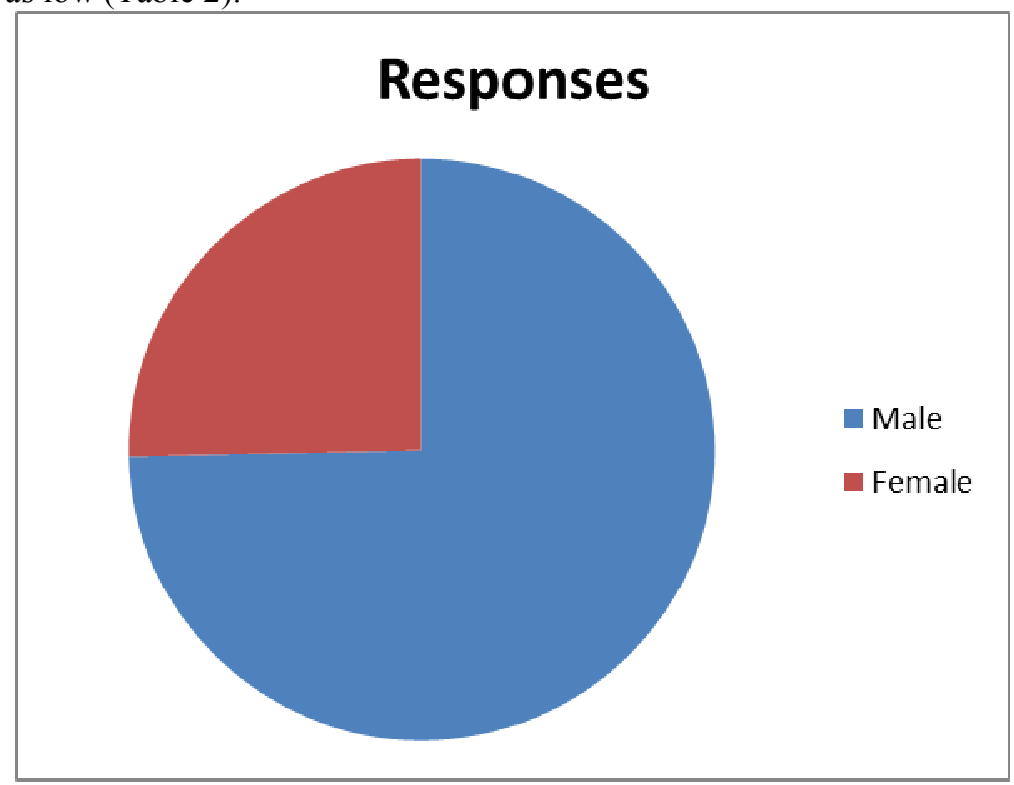

Figure 1: Gender of the Participants

The respondents age analysis is also performed, which shows that most of the respondents were 29 to 39 years, while the second highest age group was 40 to 50 years. The other two age groups were 18 to 28 years, while the last group was aged from 51 and above age group. 


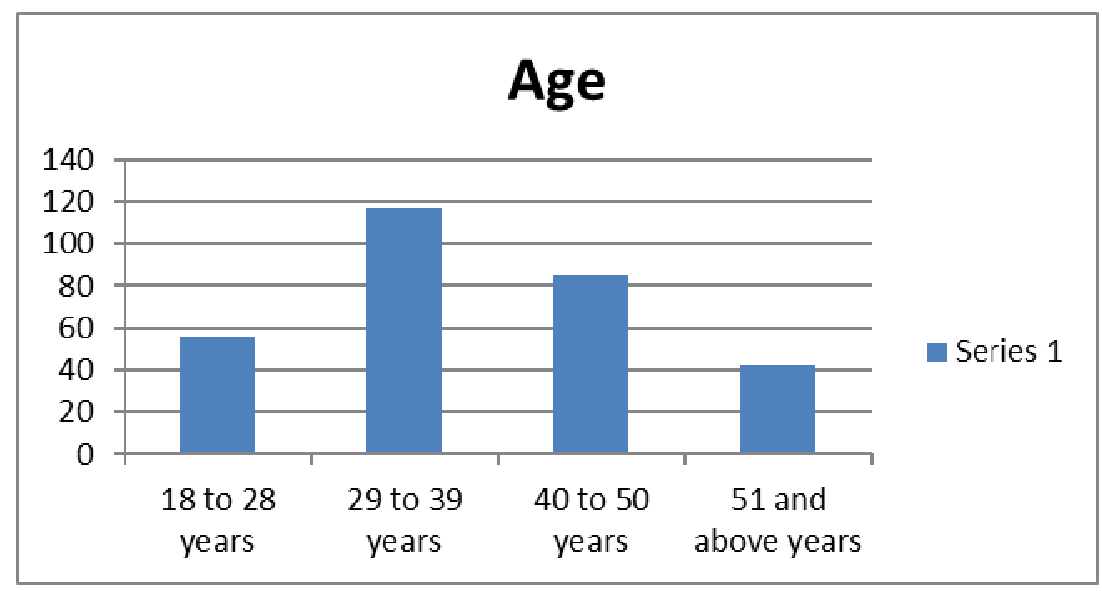

Age of the Participants

The respondents were asked that that they believed English to be a diplomatic language or not. Most of the respondents strongly agreed to it, while the strongly agreed responses were 44 . The number of neutral responses was found to be 24, while the number of disagreed responses was found to be 42 .

Table 1 Response concerning language as the diplomatic use

\begin{tabular}{llr|r|} 
& \multicolumn{2}{c}{ Frequency } & Percent \\
\hline Valid & Strongly Agree & 44 & 14.7 \\
\cline { 2 - 4 } & Agree & 190 & 63.3 \\
\cline { 2 - 4 } & Neutral & 24 & 8.0 \\
\cline { 2 - 4 } & Disagree & 42 & 14.0 \\
\hline Total & 300 & 100.0 \\
\hline
\end{tabular}

The respondents were asked whether they believed English to be a diplomatic language based on its use as the business language and increasing use in the financial transactions. Most of the respondents strongly agreed to it, while the strongly agreed responses were 14 . The number of neutral responses was found to be 28 , while the number of disagreed responses was found to be 42 .

Table 2 Responses concerning business language and financial transaction

\begin{tabular}{lr|r|} 
& Percent \\
\hline Strongly Agree & Frequency & 4 \\
\hline Agree & 216 & 4.7 \\
\hline Neutral & 28 & 72.0 \\
\hline Disagree & 42 & 9.3 \\
\hline Total & 300 & 14.0 \\
\hline
\end{tabular}

The respondents were asked whether they believed English to be a diplomatic language based on its use in the Entertainment. Most of the respondents strongly agreed to it, while the strongly agreed responses were 22 . The number of neutral responses was found to be 26 , while the number of disagreed responses was found to be 40 .

Table 3 Responses concerning Entertainment

\begin{tabular}{lr|r|} 
& Frequency & Percent \\
\hline Strongly Agree & 22 & 7.3 \\
\hline Agree & 212 & 70.7 \\
\hline Neutral & 26 & 8.7 \\
\hline Disagree & 40 & 13.3 \\
\hline Total & 300 & 100.0 \\
\hline
\end{tabular}

The respondents were asked whether they believed English to be a diplomatic language based on its use in the Book \& literature. Most of the respondents strongly agreed to it. The number of neutral responses was found to be 6 , while the number of disagreed responses was found to be 6 .

Table 4 Responses concerning Book \& literature

\begin{tabular}{lr|r} 
& Frequency & Percent \\
\hline Strongly Agree & 10 & 3.3 \\
\hline Agree & 284 & 94.7 \\
\hline Disagree & 6 & 2.0 \\
\hline Total & 300 & 100.0 \\
\hline
\end{tabular}

The respondents were asked whether they believed English to be a diplomatic language based on its 
simplicity. Most of the respondents agreed to it, while the strongly agreed responses were 28 . The number of neutral responses was found to be 26 , while the number of disagreed responses was found to be 12 .

\section{Table 5 Responses concerning Language simplicity}

\begin{tabular}{l|r|r|} 
& Frequency & Percent \\
\hline Strongly Agree & 28 & 9.3 \\
\hline Agree & 234 & 78.0 \\
\hline Neutral & 26 & 8.7 \\
\hline Disagree & 12 & 4.0 \\
\hline Total & 300 & 100.0 \\
\hline
\end{tabular}

The respondents were asked whether they believed English to be a diplomatic language based on its use as the Travel and Tourism. Most of the respondents strongly agreed to it, while the strongly agreed responses were 10. The number of neutral responses was found to be 22 , while the number of disagreed responses was found to be 32 .

Table 6 Responses concerning Travel and Tourism

\begin{tabular}{l|r|r|} 
& Frequency & Percent \\
\hline Strongly Agree & 10 & 3.3 \\
\hline Agree & 236 & 78.7 \\
\hline Neutral & 22 & 7.3 \\
\hline Disagree & 32 & 10.7 \\
\hline Total & 300 & 100.0 \\
\hline
\end{tabular}

The respondents were asked whether they believed English to be a diplomatic language based on its use in the language use in Press. Most of the respondents strongly agreed to it, while the strongly agreed responses were 18 . The number of neutral responses was found to be 8 , while the number of disagreed responses was found to be 22 .

Table 7 Responses concerning language use in Press

Frequency

\begin{tabular}{l|r|r|} 
& Frequency & Percent \\
\hline Strongly Agree & 18 & 6.0 \\
\hline Agree & 252 & 84.0 \\
\hline Neutral & 8 & 2.7 \\
\hline Disagree & 22 & 7.3 \\
\hline Total & 300 & 100.0 \\
\hline
\end{tabular}

The respondents were asked whether they believed English to be a diplomatic language based on its use in the language use in employment. Most of the respondents strongly agreed to it, while the strongly agreed responses were 10. The number of neutral responses was found to be 16, while the number of disagreed responses was found to be 18 .

Table 8 Responses concerning language use in employment

\begin{tabular}{l|r|r|} 
& Frequency & Percent \\
\hline Strongly Agree & 10 & 3.3 \\
\hline Agree & 256 & 85.3 \\
\hline Neutral & 16 & 5.3 \\
\hline Disagree & 18 & 6.0 \\
\hline Total & 300 & 100.0 \\
\hline
\end{tabular}

The respondents were asked whether they believed English to be a diplomatic language based on its use in the in science and technology. Most of the respondents agreed to it, while the strongly agreed responses were 14. The number of neutral responses was found to be 26 , while the number of disagreed responses were found to be 16.

Table 9 Responses concerning language use in science and technology

\begin{tabular}{lr|r|} 
& Frequency & Percent \\
\hline Strongly Agree & 14 & 4.7 \\
\hline Agree & 244 & 81.3 \\
\hline Neutral & 26 & 8.7 \\
\hline Disagree & 16 & 5.3 \\
\hline Total & 300 & 100.0 \\
\hline
\end{tabular}

The respondents were asked whether they believed English to be a diplomatic language based on English Language use in Media. Most of the respondents strongly agreed to it, while the strongly agreed responses were 10. The number of neutral responses was found to be 28 , while the number of disagreed responses were found to 
be 14 .

Table 10 Responses concerning English Language use in Media

\begin{tabular}{lr|r|} 
& Percent \\
\hline Strongly Agree & Frequency & 3.3 \\
\hline Agree & 10 & 82.7 \\
\hline Neutral & 248 & 9.3 \\
\hline Disagree & 28 & 4.7 \\
\hline Total & 14 & 100.0 \\
\hline
\end{tabular}

\section{Challenges Experienced}

Non-language-Pertaining problems;

The participants states that challenge appears in their job and day to day matters. Majority of the internee learners accessed the other internees nationwide, who were seniors from their college. Having contact to somebody who spoke the alike linguistic appeared vital to the fresh interns, as they stated less pressure and better utilization of time from this access. They trust that observing a known Taiwanese face assist smoothly of their emotional problem.

\section{Daily Survival}

Below are few citations where they declared the complications they faced. In the first citation, the pupil required existence expertise, as she was a fresh people conveyance system. However, the below table was characterized as a non-language-pertaining problem her frustration was compounded because she was in an atmosphere that necessitated the utilization of the language where she was not expert. Therefore, she recoiled into the Chinesespeaking surroundings when it is possible for her.

I reached in Australia atmid of the nighttime... I was residing with a senior intern in my educational institute for 7 days as my flat wasn't prepared until the upcoming week. I was there to do some work with Sandy... She discussed a bus agenda and how to upload money onto the bus pass... I accompanied her for a job for first few. (Wei, submitted in week 3)

... Firstly, I recognized where to leave the conveyance by identifying the constructions near to the motor vehicle station. Progressively, I begin to observed the outlets boards and few English vocabulary and recognized my location. I have that much knowledge to leave the conveyance at the exact location when I wanted to ....., I went to Chinese outlets frequently, as I don't have to speak English there at least. (Wei, submitted in week 4)

\section{Social and Cultural Roadblocks}

The intern undergraduatesconfrontedchallenges when struggling to mingle at work. Occasionally the internees were needed to join the social occasionsarrange by the held by the organization where they do the job. The internees stated that Western individuals converse distinctively. They had restricted communication matters to discuss. They have nil knowledge about the Westerners discussion. The below giftgranting collaborationspecified that the internee's Australian workfellowwanted her to unwrap the gift promptly to give her compliments. Whereas, individuals in Taiwan unwrap the gifts at their home after winding up all celebrations;

My biggest challenge on the job is now "making buddies." How to be friendly with my workfellows? We interact with each other load, but converse very rarely; she was a native from Australia, and are working shift was the same. Well, not only her, I was unaware of how to communicate with my Australian workfellow. In an ongoing week, we had an occasion at our job where we swapped gifts with workfellows. I kept the unwrapping of my gift for home, which my workfellow gave me, but she unwrapped mine instantly. She appeared to ponder I didn't appreciate her gift. However, that was not the case. I just senseduncomfortableunpacking a gift in the open. (Yu, submitted in week 3)

\section{Language-Pertaining Problems}

Listening and Speaking Difficulties

At the work station, linguistic issues were occasionally appeared in conversing with consumers and workfellows, particularly when the state of affairsis tangledwith the verbal conversation. The internees found it challenging when statements become unwantedly lengthy. The below is taken from the editorial of $\mathrm{Yu}$ of her journal. This preciseoccasion happened in $5^{\text {th }}$ week of her job in a city centre Chinese cafeteria, where 50 per cent of her visitors were Chinese-speaking, and the rest of the 50 per cent speaks English. She assesses the condition and chooses to inscribethis particular occasion in her editorial. Long communication, longer discussions may be an issue for the overseas internees.

This Aussie is a recurringconsumer; I have observed him multiple times. I think he recognized that I work here 
as a waitress. I haven't attended him earlier. This week, he begins to communicate with me. He observed that the Chinese visitor at the adjacent table was consuming vouchers, so he queried me about the cut-price vouchers. I recognized the guidelines for concessions by heart in Chinese. But I have not everclarified such difficult things in English. So, I vacillated... Well, the guidelines are that "If a guest is willing to pay 100 dollars' cash in advance, the guest will receive the discounted vouchers worth of 110-dollar. Discount is applicable on the Coupons from the day of your purchase. But the discounted vouchers are ineffective if the guest is already using the membership discount." When I observe him pulling out his membership card, I swiftlyfreaked. (Yu, submitted in week

\section{Foreign Accent/English Varieties.}

In the study, all the pupils who went to Singapore for the internship noticed a wide issue when conversing with the managers or workfellows who have a fluent native English pronunciation. Taiwanese pupilsnormallymeasured it problematic to understand the accent of English diversities that deviateseverely from the typicalusage of American English. Shen, one of the internees who operated at the duty-free outlet, wrote:

I was familiar with the practices. What bothered me is to having difficulty in comprehending the English of my manager from India. I presumed I needed an ample amount of time to get familiarized to his English. If you enquire me how can we help people in Taiwan, we must include the factors of indulgence with thepronunciations. We are familiar to heeding to American English pronunciations, but in the office, individuals don't voiceas they do in textbooks. (Shen, submitted in week 11)

Chia defined the methodnative Singaporeans communicate as an entertaining language style based on her involvements of connecting with her colleague, a Chinese individual who brought up in Singapore. When she communicated to her buddy in English, her buddy formedaccent that was unconceivable to her:

When we discussed, occasionally I speak in Chinese... but my Singaporean buddy prefers to mingle the languages. Occasionally, I face problem in comprehending her statements; she converses in Singlish. It is not simply English. It is a bizarre language mingled in a humorous way. I think I will slowlystart speaking Singlish. (Chia, submitted in week 15)

\section{Sentence Structure/Appropriate Usage.}

Consuming grammatically precise forms did not appear to be the main apprehension for these internees firstly. It was exciting that numerous internees did know their incapability to speak grammatically precise English statements; however, they speak that inaccurate, disjointed English expression did not restricttheir work routine.

The range hood was damaged in the kitchenette. No deep-fried or pan-fried food was accessible. That is around 50 per cent of the meal ingredients. I was concerned that I didn't be familiar with how to clarify this to them in depth. Firstly, I face difficulty in how to explain that "the cafeteria doesn't have foodstuff that needs cooking with applied oil." But the consumersentered and commenced to order. So I replied, "We aren't serving these items. We cannot stir fryfoodstuff, only steamed meals." And I displayed them the list of options. Further, I replied, "The machine is not working." I presumed that my think my clients understood. Few replied, "Oh, so no venting system." I also gained some fresh vocabulary. (Yu, submitted in week 16)

In retrospect, $\mathrm{Yu}$ revealed upon her familiarities of not being capable of communicating a grammatically precise statement in a condition that needed to offer in-depth clarifications.

Upcoming strategies of Students A mutual thread originate in the pupils'bulletins is that a few situations, the membersstated that they understood the worth of overseas internship and that they are willing to be further devoted to forming job linked expertise that can possibly help them in the forthcoming time. Acquaintance to different tradition gave the internees some distinctive perspectivesfor their forthcomingprofession. Chingdeclared that she desired to do the job in a globalvoyage line, which involvesdecent English expertise.

\section{Preparing Learners of English for Working Abroad}

Where Difficulties Arise

Concerning the fifth query of whether English introductory lessons benefit pupils overwhelmed linguistic issues, their response was not harmonized towards positivity. In multiple situations, the problems slowed from a desire to form essential necessitieslike outgoing heeding and communicating capabilities with clients, fellow workers, and managers. Their problems ascended when they have no or limited awareness of when to converse and when to listen and how to appropriately reply while experiencing a hectic day with lengthy working schedules. Shen stated the subsequent about speaking to his managers: I presumed from the body gesture, and partially from the tolerance of my Indian managers, I had no issue in comprehending the guidelines. In Taiwan, we focused on reading very intensely. Conversing and interpreting body gesture is what would help us. When the internees stated how precedingschoolroomeducationenabled their internship abroad, the majority of them declared that they utilized their knowledge they learned related to the leisure industry and hospitality readers. Nonetheless, with context to linguistic learning, they observed that the distinctive Taiwanese schoolroom did not offermultiple 
beneficial rehearses to handle with actualsituations. The usual English schoolroom in Taiwan absorbedmainly on reading, and the lecture did not offer them with the expertiserequired to manage a diversity of circumstances that may be challenged in the office.

\section{Authentic English Conversations}

As Andy, one timedeclared in his bulletin, the English discussion he received in the lodging houseseemed to be furtherrelaxed than the transcribed English he recited in readers. Andy supposed that jargon was a significantfeature of the linguistic for him to comprehend. The schoolroomeducation in Taiwan did not equip him with the expertise required to have command in professional communication. Andy believed that the trustworthy English he received was spoilt with jargon and phrases, 25 per cent of which was inconceivable to him. He educated that with an intention to converse English like a natural presenter, ample awareness of English jargon and phrases is necessary.

\section{Practice English in an English Work Setting}

Overall, they trusted that their acquaintance to English prepared them further striking as applicants for forthcoming companies. Linking work knowledge with linguistic education in an English-speaking destination deemed to offer the internees with a particular grade of self-assurance. Some supposed that they have been performing place of work jargon in their individual pitch, comprising of learning fundamentals like how to be a fine retailer, server, or guesthouse attendant. Typically, they believed that their genuine interface with English presenters all over their effort assisted them to improvise in English than if they had worked in their homeland in the same occupation.

\section{Discussion and Conclusion}

The findings presents that the use of English as the language is based on its major use in the diplomatic relation are the result of strategic, political, cultural, economic or other power's domination in the international connections. It is primarily because in the written interaction for the diplomatic affairs, usage of language is general clearly determined (frequent in mutual treaty and deal). In a general way, it depends on one of the basic rules of modern foreign rules - the law of sovereign justice of countries.

Interaction in the multilateral diplomatic affairs, definitely, is more intricate, insufficient, as well as expensive. A number of foreign organizations as well as diplomatic meetings attempt - more or less effectively to resolve the language issues by the reduction of countless chances of interaction to a considerably small quantity of opted languages - supposedly formal or official language. It is clear that the increasing democracy aspects of international affairs will result in ever increasing number of linguistics to be used in multilateral diplomatic relations along with the various other features. Whereas the concept of the sovereign justice of nations and countries, huge and small, wealthy and poor, cannot be asked, the astronomical expense to interpret at meetings along with translation of long written matter for the foreign organizations are very much in opposition of the application of this feature in real life. Moreover, the application of interpretation is unbiased, slow, mostly wrong, and usually almost wrong. As an example, nearly incredible example can be defined which translates the United Nations in various language. In Spanish, French, and English it is named as the "United Nations". However in Russian languages it is known as "Organization of the United Nations". The similar is changed, may be to Bulgarian from Russian, too.

Other situation is very famous to all of the individuals having diplomatic experience in the duties of foreign organizations or a number of other multilateral meetings: representatives who cannot speak the working or the formal languages properly (or having simply very self-critical regarding it) is not comfortable to take the stage completely, or miss the amazing points in doing so. Therefore, they remarkably decrease the input of their representatives and usually also decrease the possible worth of the ultimate outcome of the conference. Other than the question of the language solution, we can assess a more considerable feature of language along with the diplomatic affairs -the message of each and every diplomatic interaction, either oral or written.

Oral interaction is the quintessence of individual link, which, as a result, is very remarkable, even the existing foundations of diplomatic tasks. Telephone, written interaction, telegraph, fax, and currently a number of communicative systems of IT (Minitel, Internet, electronic mail, etc.) are no doubt highly supportive and very much speedy as well as productive than individual links yet they are not available for a long period time and cannot be an alternative option for a frank and private discussion with a coffee (Drave, 2017; Hasan\& Iberahim, 2019; Kirkpatrick et al., 2017).

Each verbal discussion, either it is a simple conversation, chat, sharing of opinions, official diplomatic steps, formal conference, or some other kind, particularly is a dialogue, and thus contains the features to talk and listen to the people. Talking comprises of highlighting or focusing of certain segments of a talk. Oral interaction also have various adverse impacts, for example the voice tone (either frank, solemn, private, threatening, calm, etc.), gaps between sentences or words, the sequence of various segments of the presenting message, gesture, facial 
expressions, smile and a number of other aspects as well (Drave, 2017; Kirkpatrick et al., 2017).

Among the classical elements of "diplomatic" language is a particular low tone, a type of delicacy. It is appropriate to state that the actual burden of words and phrases in diplomatic official slangs is much powerful than such similar terms in common conversations or daily routine. Some of the examples are: the deputy foreign affairs minister invites the diplomat of a neighbor country to his office in the afternoon and shows the "government's concern to report the press of the ambassador's country which is not in accordance to maintain peace with the present healthy link between both of the countries." Interpreted to official language, this refers to "we trust that your state government is enhancing the unpleasant, even confrontational, press in opposition with our state and by doing this you have crossed the controls and I need to give warning that we will not accept it further." The reality that the diplomat has been called by ministry after the official timings shows that the domestic governing bodies focuses the issue to be immediate and even more than common pattern of mutual relations (Drave, 2017; Hasan\& Iberahim, 2019; Kirkpatrick et al., 2017). If it is added by the minister that "he is scared that the prolongation of these activities can show impact adversely on the relation between both of the states", it refers to that such relations are disturbed already (quite obvious, or else there would not be unpleasant press nor violent feedback on the other end), therefore one can expect the delay of an already acknowledged mutual visit or acknowledgement of a mutual coordination deal. If the minister is saying that he is scared that "his state government will not be capable to control the agony and anger in the media or stop the emotions in the lower house parliament further" the diplomat will not be wrongly translating it as a declaration of a huge confrontational attack against the country, may be even of a ferocious debate in the parliament with an most unpleasant allegation. There are various certain articulations in the language of diplomatic affairs which can used in different aspects of diplomatic practices for example for the redaction of press releases - "pleasant environment ", "closeness of opinions", "total freedom", etc. - for debates (therefore the variance between supposed hard and soft debaters, though I acknowledge only the difference between bad and good ones!), for informal links apart from the professional one and for the casual events, to participate in the foreign meetings, for the outcomes of global deals and agreements, etc.

\section{References}

Dasselaar, C. (2016). English Versus Native Language in Digital Diplomacy.

de Carles, N. R. (2019). Shakespeare's Diplomacy: A European Language in Conversation with the World.

Drave, N. (2017). Hong Kong Diploma of Secondary Education (HKDSE) English Language Level Descriptors: Stakeholder Recognition and Understanding. Learning and Assessment: Making the Connections, 64.

Friedrich, P. (Ed.). (2016). English for diplomatic purposes. Multilingual Matters.

Hasan, H. B., \& Iberahim, S. B. (2019). English Language Proficiency And Its Challenges Among Students From Diploma Of Mechanical Engineering. Indonesian Journal of Education Methods Development, 5.

Kirkpatrick, A., Subhan, S., \& Walkinshaw, I. 4 English as a lingua franca in East and Southeast Asia: Implications for Diplomatic and Intercultural Communication. English for Diplomatic Purposes, 75.

Kisin, N. ENGLISH AND SPANISH: FAIR COMPETITION WITH FRENCH AS NEW LANGUAGES OF DIPLOMACY?.

Kulinska, K. (2018). Linguistic barriers in modern diplomacy-the case of sign language.

Mori, Y. (2020). English as a Lingua Franca in International Dinner Conversations: Towards Mutual Understanding.

Oglesby, D. M. (2016). Diplomatic language. The SAGE handbook of diplomacy, 242-254.

Walkinshaw, I., Mitchell, N., \& Subhan, S. (2019). Self-denigration as a relational strategy in lingua franca talk: Asian English speakers. Journal of Pragmatics, 139, 40-51. 